\title{
Progressing Towards Environmental Health Targets in China: A Systematic Review of Achievements in Air and Water Pollution under the "Ecological Civilization and the Beautiful China" Dream
}

Henry Asante Antwi ( $5103150217 @ s t m a i l . u j s . e d u . c n)$

Center for Health and Public Policy Research, Jiangsu University

\section{Systematic Review}

Keywords: Environment, Health, Ecological, Civilisation, China, Air, Water Pollution

Posted Date: November 30th, 2020

DOI: https://doi.org/10.21203/rs.3.rs-116974/v1

License: (1) This work is licensed under a Creative Commons Attribution 4.0 International License. Read Full License 


\section{Abstract}

Despite the positive effect of industrialization on health and quality of life indicators across the globe, it is also responsible for the release of chemical toxins into the environment and has nurtured numerous environmental disasters with severe health effects. China alone produces more than a third of carbon emissions in the world and currently has the second highest number of pollution-related deaths, after India. There is no issue that underscores the challenges of environmental crisis in China than the gradual acceptance of the existence of the cancer villages. These are entire towns that have been completely written off as so polluted that simply living there is synonymous with high rate of cancer risk. For years, residents and advocacy groups in villages such as Wuli, Yanglingang, Yangqiao and additional 459 identified cancer villages have waged a desperate war to turn the attention of government to the high risk of stomach, liver, kidney and colon cancer in these areas located near heavy industrial complexes. China responded by promoting an ecological civilization and a beautiful China dream as its sustainability blueprint in 2012. Today, this blueprint has been engraved into the national ideology for socio-economic and political orientation. This review therefore revisits the progress made towards environmental health targets under China's sustainable development strategy. The study systematic explores the extant works on air and water pollution since the "Ecological Civilization and the Beautiful China" Dream.

\section{Introduction}

Environmental health crisis has become a common theme in several national and international advocacy and policy interventions since the early 1960 s. According to Lian (Liang and Yang 2019) the impact of environmental pollution is significant and multifaceted. It includes damage to human health, social conflicts, and economic losses. Apart from the indirect effect of global warming or carbon emissions on overall human health, certain forms of environmental exploitation are directly linked to myriad environmental health crisis that affect populations exposed to them (Liu and Lin 2019). For example, drywalls are predominantly produced in China at a cheaper price but this has the potential to emit high levels of sulphur gas which corrodes electrical wiring but this can cause acute breathing problems, headaches and bloody nose for the occupants of the building (Li, Fang et al. 2019).

According to Tan, Yang et al. (2019) phthalates which is a household contaminants emitted by vinyl floors can cause autism among kids. Similarly, high exposure to high levels of exposure to polybrominated diphenyl ether (PBDE) flame retardants which is used in the manufacture of cushions, carpet padding and mattresses can cause transmit poisonous chemicals in the bloodstreams can ultimately lead to infertility and abortion among women. The extant literature is replete with randomised control trials that validates the relationship between certain environmental exposures and increase rates of obesity, diabetes, cardiovascular and nervous systems diseases, cancer, Asthma, allergies etc (Mohsen, Wang et al. 2019).

Richard Carson's 1962 best seller "silent spring" represents a watershed moment in unveiling the unprecedented health calamity that was furtively been perpetuated through unguarded economic production and exploitation of the environment across time. Similarly earth day 1970 gave birth to a new global action for environmental consciousness (Dutheil, Baker et al. 2020). On this day individual advocacy groups that were fighting individual environmental challenges such as oil spills, pollution from factories and power plants, pollution from raw sewage and toxic dumps, pesticides and freeways, among others rallied round as common ally and broke through political barriers to fight environmental injustice(Aunan, Hansen et al. 2019).

In the United States of America where these advocates emerged, the leaders successfully enlisted the support of both Republicans and Democrats, urban and rural dwellers, rich and poor and more importantly business and labour union leaders to encourage corporate enterprises to aspire towards conscious production and business(Bian, Song et al. 2019). These advocacies ultimately led to the establishment of the environmental protection Agency in the US. The 1970 event also inspired the passage of a wide range of pro-environmental legislations in the US such as the National Environmental Education Act, the Occupational Safety and Health Act, and the Clean Air Act which were the first of their kind. 1972 and 1975, the Congress of the United States supported the pro-environmental advocacy by enacting environmental laws such as the Clean Water Act, the Endangered Species Act and the Federal Insecticide, Fungicide, and Rodenticide(Ebrahimi, Khalili et al. 2020).

In China, environmental pollution and health related crisis took time to mature. Yu, Yang et al. (2019) explain that the quest for economic breakthrough made the subject of minimal importance to the China's government where coal and other pollutants was the pivot of large scale production. Overtime succeeding generations of Chinese leaders have entrenched environmental, social, and governance issues in national civilisation blueprints culminating in China's ecological civilisation and the beautiful China dream (Wang, He et al. 2019). Even though China does not fall within the top 20 countries with the highest per capita emissions, it ranks first among the top 15 countries that generate $72 \%$ of $\mathrm{CO}_{2}$ emissions in the world.

Specifically, China generates approximately $28 \%$ of global carbon emissions and this is almost a double of the carbon emissions generated by the US which is the second highest ranked country (Yang, Lin et al. 2019). The United States itself is responsible for more than twice the level of third-placed India.

Significantly, the remaining 180 countries of the world collectively produce nearly $28 \%$ of the global total carbon emission which is close to the amount produced in China alone (Liang, Wang et al. 2019).

Faced with the glaring environmental catastrophe, environmental concerns and environment health in China has evolved from a mere public health and social policy sidebar to a matured independent sector within China's public health system and across the globe(Mohsen, Wang et al. 2019). The objectives are to role monitor and address hazardous physical, chemical, and biological agents that impact human health (Zhang, Zhou et al. 2019). There is an increasing call for policies and programs aimed at reducing chemical and other environmental exposures in air, water, soil and food to protect people and provide communities with healthier environments.

China has responded by promoting its ecological civilisation and the beautiful China dream. In his reported to the $17^{\text {th }}$ National Congress of the Communist Party of China (CCP) in 2012, then President Hu Jintao proposed a new "ecological civilisation" ideology to place "sustainability" on equal pedestal within China's economic development agenda (Wang, Hu et al. 2019). President Hu himself asserted the fact that his idea of ecological civilisation was not an initiative to fill a theoretical vacancy in its socialism with Chinese characteristics, but rather a future-oriented guiding principle based on the perception of the 
extremely high price we have paid for our economic miracle (Hao, Guo et al. 2020). The initiative came at a time when $62 \%$ of rivers in China had been seriously polluted and $90 \%$ of water ways flowing through urban areas had become so contaminated that nearly 300 million Chinese people lacked access to clean drinking water (Bian, Song et al. 2019). It was also at a time when several localities could not fulfil global pollutant emission reduction and energy saving quotas (Ma, Jia et al. 2019).

In 2015, China formally adopted a comprehensive ecological civilisation master plan for systematic and institution reform. This master plan among others listed series of principles and objectives needed to be achieved. The master plan envisaged that by 2020, China would have completed the institutional set-up" to achieve ecological civilization(Zeng, Cao et al. 2019). In July, 2018, President Xi Jinping received the approval of the 18th National Congress of the Communist Party of China to engrave the "ecological civilisation and the beautiful China dream" into the country's ideological framework for socio-economic development popularly known as socialism with Chinese characteristics (Yongjian, Jingu et al. 2020).

Its half way through the year 2020, (the year predicted in 2015 to complete the institutional set-up" to achieve ecological civilization), yet success is still far in sight. China has made a modicum of achievements towards environmental protection but air and water quality in China remains unimpressive. Unfortunately China's geopolitical position often suffocate, the theme in most of the commentaries and studies about China including environmental concerns(Zou, You et al. 2019). This has created a paucity of studies that systematically and independently evaluates the progress of a new China in the eyes of sustainable environmental performance. The objective of this review is to fill this gap by employing generally accepted blue prints to interrogate the current stock of studies about China's environmental drive. The objective is to systematically track China's progress towards environmental health targets within the complexities of air and water pollution since the proposal of its "ecological civilisation and the beautiful China" dream

\section{Methods}

The procedures for conducting systematic review outlined in the PRISM model was applied in carrying out the systematic review. The PRISMA model (The Preferred Reporting Items for Systematic Reviews) was developed by a consortium of experts who developed it as an enhancement of the QUOROM Statement (QUality of Reporting Of Meta-analyses) which was developed in 1991. The entire model outlines the systematic procedure and graphical description of the set of activities that a researcher must undertake to obtain a good systematic synthesis of the extant literature. Prior to the PRISMA model, other systematic scoping strategies dominated but since 2009.

The predecessor QUOROM Statement (QUality Of Reporting Of Meta-analyses) was developed in 1999 to guide the process of systematically reporting metaanalysis of randomized control trials. The PRISMA Model was however developed in 2009 to improve the quality and the transparency benchmarks of the reporting process of other forms of systematic reviews. Figure 1 is the flow chart of the PRISMA model applied to this research.

As in the case of Baranovitch (Baranovitch 2019), environmental health was treated as multidimensional constructs. It is influenced by political, economic, socio-cultural, technological, ecological and legal and other invisible factors. This is more so in the case of China which has topped the world environmental pollution chat for so many years.

The complexity and multidimensional nature of environmental concerns is well articulated by Ahmed (Ahmed, Asghar et al. 2020) who argues that causal linkages between pollution sources, exposure pathways and impacts to environmental quality and human health and other environmental problems is like a maze with confusing routing paths. This complexity of the relationships between environmental factors and human health takes into account multiple pathways and interactions that come closer in one instance and move apart with visual illusions that confound even the most developed economies. Moreover, some of these factors have unidirectional effect whereas others have bi-directional or multidirectional influence environmental health. China's ecological civilisation attempts to design a seamless set of relationship that connect these factors and harness them into a beautiful China dream with high air and water quality. To this end the methodology applied to carry out this research took cognisance of the dynamic and constantly evolving nature of environmental health, air quality, water quality etc. Firstly environmental drivers of environmental health namely the air and water quality were extracted from the current stock of literature and clustered summarized, analysed and reported accordingly.

\section{Search Strategy}

Between April 2019 and April 2020, a search was conducted among 8 bibliographic databases to obtained previous studies on environmental health indices in China especially, air quality and water quality. Initially 12 databases were shortlisted but were screened down to 8 after screening the related contents, degree of access to database and the quality of information. The final 8 shortlisted databases used in the study were the Web of Science, SCOPUS, EBSCO, Directory of Open Access Journals, Education Resources Information Center, Pro-Quest, Digital Library of the Commons Repository and Social Science Research Network. A distinct and hierarchical search cluster term i.e. main topic (environmental health, environmental pollution, and environmental health policy), subtopic (air pollution, water pollution ecological civilisation, beautiful China dream), specific theme (cancer villages, groundwater quality, lakes and rivers quality etc) were defined to search information in each database.

The author applied narrative search procedures were also applied to select the main articles. In line with the requirements of the PRISMA model, search terms were combined through Boolean operators like AND/OR. The author and well-trained research assistants (mainly PhD candidates) entered each of the key subject terms, main topics, subtopic, and themes individually in English language. To improve precision of the searches and sensitivity, truncations and wildcard characters were used. The initial search did not discriminate between the type of publication, time frame for publication, design of the study and the publication mode (peer review or others). The initial search yielded a total of 2063 papers as shown in the PRISMA flow chart in figure 1. The numbers of 
articles obtained from the database were supplemented with 209 additional articles that were procedure by hand searching other sources such as Google Scholar and Science Direct. Thus a total of 2272 articles were retrieved after the initial task..

\section{Screening}

The articles were screened using two steps. Firstly the article was screened to remove duplicate articles. This was done by importing all the 2272 articles into four citations software namely. The four citation software was used simultaneously to serve as a validation technique or ensure that they all returned the same results after the process. This was conducted by the support of the researcher and trained research assistant with specialisation in library and archival reference management system. A total of 1321 duplicates were detected and removed from the four citation software. The final compilation was compared between the four citation software for a second time. The researcher then manually inspected and validated the final list of qualified articles to move to the next step. Thus the remaining 951 were then carried to the next level of analysis.

\section{Eligibility}

The researcher applied strict eligibility criteria to ensure that only well qualified articles are carried over to the final review phase of the systematic review. The first criterion was the language of publication. The study admitted only articles published in the English language. Secondly, the article should be focused on China and should have been published within the last 5 years were admitted. This timeline was agreed to be the first time that the then Chinese President (Hu Jintao) proposed the ecological civilisation agenda. Next, the selected article must be a peer reviewed article (quantitative, qualitative and mixed, primary or secondary research). In the event the selected article is not a peer reviewed article, then it must be a report by a state agency, internationally recognised bodies such as the United Nations, IMF, World Bank etc or highly respected professional body known for their involvement in the area of environmental health across the globe.

A typical example of such an institution is KPMG, Price Water House Coopers, international development agency or an official document of a multinational company. In any specific case the decision to include an article was solely determined by the author even though the research assistants offered their full professional advice however goodness of fit of articles with the eligibility criteria was the main consideration to include an article. All publications that were in dispute were validated and resolved through a hierarchy of other considerations and deliberations among the research team members until consensus was reached to accept or reject its inclusion. At the end of this process a total of 44 articles were shortlisted for the final extraction process.

\section{Data Extraction and Analysis}

Finally the data extraction and analysis was conducted to summarise the shortlisted articles. The standard practice is to qualitatively evaluate them and synthesize in tandem with the objectives of the research. This activity was conducted through a four-step process using content analysis procedure. The eligible articles were first scanned for environmental pollution, environmental health, air pollution, water pollution reports, statistics, targets, challenges, policies and strategies in China. In the second step, the extracted information were coded and extracted by the research team based on an inductive approach. Overlapping information from different research articles were counted only once. In the third stage the quality of research design and methodology and basis of report (where report is not a peer reviewed article) were strictly assessed. In the fourth stage, the main information (theme) and dimensions of study of each article was extracted into a matrix. They were then discussed with the expert research assistants in April 2020. The feedback was integrated into the final analysis.

\section{Analysis}

\section{Description of Studies}

The descriptive characteristics of the final 44 articles that were extracted for final analysis have been presented in table 2 . The result shows that 16 of the articles were focused on air pollution alone whereas 22 of them focused on water pollution. The remainder focused on pollution in general or climate change. $50 \%$ of the studies involved lab based experiments whereas $20 \%$ were quantitative studies. $30 \%$ of the studies were qualitative studies. The 44 studies were conducted across the length and breadth of China. One of them compared a situation in China and the United States. The range of study covered most of the provinces in Greater China. At least a research paper emanating from each of the six main zones in China namely; Northwest, South West, North, North East, South Central and East China was reviewed in this study. There were more studies undertaken in Southern part of China (63.9\%) than there were from the northern part of the country. The theme of the studies reflected the objectives of the research outlined in the first section of the study and the details are shown in table 2.

\section{Study Quality}

The quality of the selected studies was evaluated using the Mixed Methods Appraisal Tool (MMAT). The MMAT method has been used for more than 10 years and is considered a robust technique for systematic review. The MMAT method is preferred in assessing the quality of the articles because it enables a systematic reviewer to accurately evaluate the quality of articles conducted using quantitative, qualitative and mixed research methods and this is the case in this study. 
This view is supported in the work of Pluye \& Hong (2014) who argues that overtime the MMAT tool has become a leading quality assessment tool to determine the inclusion and exclusion of quantitative, qualitative and mixed methods articles for systematic reviews. The assigns scores to specific research quality benchmarks. The aggregation of the scores is used to determine the quality of the article.

The MMAT scores obtained for the articles reported in this study is presented in table 2 . The scores ranged between $25 \%$ and $100 \%$. 18 studies received $70 \%$ rating based on the MMAT criteria, whereas 14 studies (80\%) received $75 \%$. Similarly, 20 studies received $80 \%$ and only 5 scored $100 \%$. The most frequently occurring weaknesses in the selected studies were the failure to disclose the influence of the researcher's background and orientation on the research process and outcome and the role of funding agencies in the research process. A number of the studies also lacked clear description of the sampling procedure, especially with quantitative studies. The reason for selecting to study specific cases such as air pollution, water pollution, cancer villages, etc were also not elaborated by most of the studies.

\section{Main Environmental Health Challenges Facing China}

\section{Air Pollution}

A number of the selected studies acknowledge the fact that the Chinese government has shown some high level of commitment to environmental concerns within the last decade better than it had been prior to this. Some of the new studies also confirmed the COVID-19 which incidentally started in China may have contributed to enhanced air quality in China within the first six months of 2020 (Muhammad, Long et al. 2020). This is because most of the industries factories that contribute heavily to air pollution were shut in addition to reduced human activity.. This notwithstanding majority of the studies asserted that irrespective of the government's effort at controlling environmental pollution in China, environmental health issues especially air pollution, water pollution, desertification and the increasing number of cancer villages remains a challenge (State of Ecology \& Environment Report Review, 2020).

For many people in China, poor air quality is a normal daily challenge as it persists in several parts of China. Generally, any air quality rating that exceeds 300 on the World's air quality scale means that the air is unsafe for breathing (Yang, Yuan et al. 2019). Technically, people living under such air conditions must be advised to stay indoors with an air purifier running and they must remain as motionless as possible to reduce excessive inhalation of bad air. However, the case in China is often different. In some instances, air quality in Beijing alone can exceed the 300 threshold over 20 consecutive days (Peng, Zhao et al. 2020). In some of the major industrial cities in China air quality ratings above 500 have become usual and this may persist over several days. For example, in January 2017, an air quality rating of 886 was recorded in China and this is interpreted as eye bleeding because it is comparable to living in a smoke lounge (Yongjian, Jingu et al. 2020).

Three reasons are extracted from the studies as accounting for this state of excessive pollution. A strand of studies such as (Li, Wang et al. 2019, Xu, Sun et al. 2019, Zhao, Geng et al. 2019, Zou, You et al. 2019) blame this phenomenon on high number of manufacturing industries dotted in Chinese whose emissions is crippling environmental health in these cities. Other studies such as (He, Liu et al. 2019) equally lay the blame on the burning of coal for energy which until recently had been China's main source of electric power plan to power its economic development. Currently, $47 \%$ of all coal burnt in the world is done in China. This is nearly the size burnt by all other countries in the world. As explained in Guo et al (Guo, Zhang et al. 2020), Beijing's poor air quality is exceptional because it is surrounded by a vast network of coal burning power plants.

Ma, Liu et al. (2019) offer the third reason for the high level of air pollution in China and its impact on environmental health. It is inferred that in other large cities such as Shanghai, Guangzhou, Hangzhou, Nanjing, Shenzhen, Chongqing and rapid increase in the number of motor vehicles have shifted the conventional coal combustion type of poor air quality to a mixed coal combustion/motor vehicle emission type. Currently Sulphur dioxide molecule ( $\mathrm{SO}_{2}$ ), nitrogen dioxide $\left(\mathrm{NO}_{2}\right)$ and inhalable particles ( $\mathrm{PM}<10 \mu \mathrm{m}$ in aerodynamic diameter; PM10) are the main pollutants of critical concern in China (Liu, Kiesewetter et al. 2019). In general while $\mathrm{SO}_{2}$ and $\mathrm{NO}_{2}$ levels are not very different across China (national annual average $\mathrm{PM}_{10}$ of $121 \mu \mathrm{g} / \mathrm{m}^{3}$ nationwide) the PM levels in southern cities (annual average $\mathrm{PM}_{10}$ of are $102 \mu \mathrm{g} / \mathrm{m}^{3}$ ) are much lower than those in the northern part of the country (annual average $\mathrm{PM}_{10}$ of are $\left.140 \mu \mathrm{g} / \mathrm{m}^{3}\right)$.. On the other hand, the annual average concentrations of $\mathrm{SO}_{2}$ and $\mathrm{NO}_{2}$ nationwide are $66 \mu \mathrm{g} / \mathrm{m}^{3}$ and $38 \mu \mathrm{g} / \mathrm{m}^{3}$ respectively which far exceed global allowable limits respectively (Liu, Kiesewetter et al. 2019).

A number of the selected studies reported that air pollution in major cities such as Beijing is a cause for concerned for the Chinese government. Indeed Zheng, Wang et al. (2019) report that China is host to 16 of the 32 most polluted cities in the world. However, the debilitating air quality in Urumqi (Urghur-Xinjiang Autonomous Region), Lanzhou (Gansu Province) and Linfen (Shaanxi Province), Xingtai, Baoding, Shijiazhuang, Handan, Hengshui, Tangshan, Langfan, Cangzhou, Zhengzhou, etc that consistently ranks on top of the list of the world's most polluted places is a matter of great concern within and outside China since these areas are among the least developed parts of China (Yu, Zhu et al. 2019).

In a survey conducted among Linfen's residents in the Shaanxi province where two thirds of China's coal is produced, the residents literally claimed to choke on coal dust in the evenings ( $\mathrm{Li}, \mathrm{Hu}$ et al. 2019). To ameliorate this challenge, the authorities in Linfen city has instituted measures to replace small, highly polluting plants with larger, cleaner, more regulated facilities, to cut toxic emissions and shift from coal to gas for central heating. Even though these initiatives have provided some interventions, these are not significant enough to overturn the many years of accumulated environmental health damages emanating from coal mining in the city and its environs(Ito and Zhang 2020).

Environmental pollution and the consequential environmental health crisis for Urumqi is very critical considering the fact that it is located in one of the poorest autonomous regions in China. Together with Tibet, they form the heartbeat of political and religious resistance against the Chinese Communist Party(Baranovitch 2019). Further, Urumqi and other cities in the autonomous region are home to nearly $11 \%$ of the minority ethnic groups in China and these have a history of poor access to healthcare among other socio-economic challenges. This is compounded by the fact that the territory lie nearly 900 meters above sea level which presents existing breathing difficult at such a high altitude even with normal clean air(Sierra-Hernández, Beaudon et al. 2019). 
Like Linfen city, Urumqi's air poor air quality emanates from the large number of coal-fired power plants in the city that dampens the overall air quality. Sometimes an underground coal fire can burn continuously for 50 years. A typical example is the Terak minefield underground fire that burnt continuously for more than 50 years until it was put out in 2007 after persistent protest from within and outside China(Liang, Wang et al. 2019). Urumqi holds the dubious honour of going 119 continuous days with air quality exceeding Grade II, which is the highest number of days in the region(Li, Huang et al. 2020).

The precarious difference between Urumqi's pollution and those in other provinces is that desulphurization technologies used in other provinces are barely available or utilized in Urumqi. This leads to high retention of $\mathrm{SO}_{2}$ particles(Li, Huang et al. 2020). The situation has further aggravated the already dark sky in Urumqi since lack of desulphurization alone contributes nearly 70,000 tons of toxic gases per year since the 1950s. Urumqi has a lot of underground coal fires which are hazardous because it cause cave-in when the coal turns to soft ash below the surface(Chen, Lu et al. 2019). The 2017 Xinjiang Statistical Yearbook showed that Urumqi recorded the worst $\mathrm{NO}_{2}$ and $\mathrm{SO}_{2}$ and the third worst $\mathrm{PM}_{10}$ levels among all major cities in China in 2017 (State of Ecology \& Environment

\section{Report Review, 2020).}

.Lanzhou is the capital city of Gansu province in north-western China. Lanzhou city also features prominently in the air pollution in China. Significantly Gansu province is the poorest of the 34 provinces, municipalities, special administrative regions and autonomous regions in China(Ma, Ma et al. 2020). The authors reveal that in 2011, Lanzhou was ranked the most polluted city in China but the status has passed on to Xingtai city the Hebei province not because pollution has improved in Lanzhou but has increased dramatically in Xingtai city (Liao, Jin et al. 2020). Air pollution from sand storms, factory and traffic emission is the main source of the crisis.

Unfortunately Lanzhou is surrounded by mountainous areas some of which peak up to $500-600 \mathrm{fts}$ above sea level. This trough-shaped topography traps air pollutants at the ground level, resulting in well-documented poor air quality (Zheng, Peng et al. 2020). Periodic analysis of the characteristics of Lanzhou's ambient air pollution shows that its $\mathrm{PM}_{10}, \mathrm{SO}_{2}$ and $\mathrm{NO}_{2}$ concentrations have consistently exceeded allowable health guidelines (Liu, Zhang et al. 2020). Previous research studies have consistently linked poor air quality in Lanzhou to the high birth defects, low birth weight, Pre-term birth, intrauterine growth retardation, infant death and disability and other respiratory diseases.

In a population based control study, Zhang, Gong et al. (2020)found at that congenital malformations of cardiac septa were associated with exposure of pregnant women to $\mathrm{PM}_{10}$ especially in the $2^{\text {nd }}$ trimester of their pregnancy while $\mathrm{SO}_{2}$ exposures at any point during the pregnancy could lead to similar results. A synthesis of the findings of time series research in major Chinese cities namely Beijing, Shanghai, Chongqing, Shenyang, Wuhan, and Taiyuan further corroborated the existing notion that persistent exposure to minimum and short-term air pollution is associated mortality or morbidity(Liu, Zhou et al. 2020). Specifically the authors found out that morbidity and mortality risk estimates per unit increase in air pollution levels among the Chinese population is similar to the magnitude of risk estimated in other parts of the world. A recent study in Hong Kong, Wuhan and Shanghai supports the evidence of short-term risks(Yang, Liu et al. 2020), with substantial health effects detected at air pollution levels below minimum air quality standards in China.

Currently, a new national-level air pollution time-series study, the China Air Pollution and Health Effects Study (CAPES), is under way. In addition, several ongoing panel studies are examining associations between air pollution and subclinical health outcomes. These panel studies should provide a unique opportunity to assess the public health benefits of air pollution reduction in a city where air pollution levels have been high. China's main strategy to overcome air pollution is an expansion in renewable energy capacity. The goal of the government is to spend $\$ 360$ billion on renewable energy by the end of 2020 . In addition it is also the goal of the Chinese government to increase the composition of renewable energy in the national electricity consumption to $35 \%$ by 2030 . If these standards are met, China would have produced renewable energy capacity of the same scale as the total electricity demand for the US. This would represent half of the world's green building floor space. China has a proven track record of achieving ambitious long term renewable energy goals set forth within China's Five Year Plan

\section{Water pollution}

The problem of water pollution in China was mentioned by more than half of the selected articles. These studies admit that water pollution in China is receiving some degree of attention in China compared to what pertain a decade ago(Li, Liao et al. 2019). It is pointed out however that the numerous effort undertaken by government to control water pollution notwithstanding, it remains a major environmental health challenge in China. (He, Zhong et al. 2019) recalls the state of water pollution in 2013 when more than 16,000 swine carcasses were found floating in Shanghai's famous Huangpu River. This event embarrassed the Chinese government and became a major foundation for rejuvenated government crackdown on water pollution.

This is because the Huangpu River passes through Shanghai's skylines and major tourism spots. Besides, it is the main source drinking water for the over 25 million inhabitants of the megacity. The case in Shanghai was only the tip of the iceberg of an endemic water pollution crisis across the length and breadth of China (less prominent cities and villages) without attention(Fan, Zheng et al. 2019).

Ma, Sun et al. (2020) explains that the post "Huangpu River pollution debacle" on water pollution that started in 2013 was ruthless at the beginning but the alacrity and strictness only lasted for two years. Since then, a number of other similar crises have also emerged across the length and breadth of China that continues to put water quality into dispute. For example, hundreds of dead piglets wrapped in sacks were found floating in a river near Fuqing in China's Fujian province whiles $100,000 \mathrm{~kg}$ of poisoned dead fish were scooped up from the Fuhe River in Hubei province in China in 2013. In 2020, untreated urban sewage was again scooped from the Baoding city end of the Fuhe River as it flows into the Baiyangdian Lake. In 2016, 1,000 dead ducks were scooped from the Pengshan River in the Sichuan province. As observed by He and Li (2020), China's strong economic gains from the textile industry has a paradoxical effect on water pollution in many different parts of the country.

Many dye manufacturing and textile making companies secretly dump dye and other dangerous chemicals in strategic water bodies thereby that are the main source of drinking water for towns and villages. For example, in 2011 and again in 2017, the colour of parts of the Jiang River in Luoyang turned completely 
red after industrial dyes were illegally dumped by a nearby chemical plant. The resulting negative publicity and the environmental health effect inspired a new state-wide clamp down on such heinous crimes (Wang and Song 2020).

However these interventions are not well implemented and have emboldened other industries to do the same under cover or without deterrent sanction.

The environmental health dangers of dumping dye is further explained by Lin, Shen et al. (2020)who reveals that most of the textile manufacturing companies dotted across China uses nearly 8000 synthetic chemicals to bleach, treat and brighten clothes. Additionally, finishing processes in cloth making require the use of additives that are dangerous to human health, marine life and the environment as a whole. Azo dye for example is the most frequently used dye in the fashion industry and responsible for high intensity hues and poppy red. However when Azo dye breaks down and metabolizes, they become carcinogenic (cancer causing property). Unfortunately, arylamines and other chemicals emitted from the azo dye used in the textile industry do not easily dissipate but evaporate into the air or are absorbed through the skin(Ma, Zhao et al. 2020).

The current stock of literature affirm that any human contact with synthetic dyes can trigger allergic reactions, skin irritations and rashes or at worse cancer (Li, Fu et al. 2020). A key feature of water pollution in China is the persistent dumping of Azo dyes into rivers by unsuspecting enterprises which contributes to the negative environmental health conditions in China. The persistence of dye related diseases in China informed the decision of the National Standard for the People's Republic of China to reaffirm the prohibition of 2, 4 and 2,6-xylidine which are chiefly used as intermediate for azo dyes(Feng, Shao et al. 2020).

Beside the use of the dyes, factories still freely discharge their water into lakes and rivers due to weakened regulation and enforcement. Wang and Zhu (2020) speculate that in the case of China, the enforcement lapses are sometimes genetically engineered due to the linkages of top officials with the economic benefits of these industries but the allegations are yet to be proven. That notwithstanding evidence of unsafe factory leakages into water bodies about in many of the provinces in China. In 2013 and also in 2018, for example, a chemical company was found to have leaked benzene, which is a known agent that causes cancer into one of the tributaries of River Huangpu resulting in the hospitalization of more than 20 people. Most of these rivers serve as the main source of drinking water for communities along the banks of the river.

Cui, Dong et al. (2020)explains that beside official complicity, a major reason why water pollution appears to be a daunting challenge in China is the demand for cheaper products. Moreover, multinational companies consistently ignore the need to scrutinise the environmental practices of their suppliers and rather focus on cheaper prices. To this end even though national development in China especially in its rural areas seems to have lifted a lot out of poverty, there is a paradox of health crisis as a concomitant of economic development.

According to Jiang, Chen et al. (2020) water pollution in China doubled in 2019 from governments predicted rate because the government underestimated the impact of the contribution of agricultural waste to water pollution. In Sun (Sun, Peng et al. 2020) it is revealed that farm fertiliser as a major contributor to water contamination in China has accentuated since 2015. A study conducted by Ebrahimi, Khalili et al. (2020) revealed that the main fertiliser based toxic contained in polluted Chinese rivers were arsenic, fluorine and sulphates which are directly linked to high rates of liver, stomach and oesophageal cancer. It is also inferred in (Liu, Liu et al. 2020, Zhang, Wang et al. 2020) that in the case of China, excessive pollution induced algae blooms have caused the surface of its lakes and water bodies to turn a bright green with greater problem lurking beneath the surface. For example, it is estimated that about $90 \%$ of groundwater in Chinese cities and towns are highly contaminated despite the closure of several pollutant sources and most of rural areas in China lack effective waste water treatment system.

In the view of Liu, Liu et al (2020), the water pollution cases in coastal China is worse than water pollution in other parts of the country due to the presence of several manufacturing belt that contributes to pollution. According to Gao, Shahab et al. (2020) there is no issue that underscores the challenges of environmental crisis in China than the gradual acceptance of the existence of the cancer villages. These are entire towns that have been completely written off as so polluted that simply living there is synonymous with high rate of cancer risk. For years, residents and advocacy groups in villages such as Wuli, Yanglingang, Yangqiao and additional 459 identified cancer villages have waged a desperate war to turn the attention of government to the high risk of stomach, liver, and kidney and colon cancer in these areas which are mostly near heavy industrial complexes. In a village such as Huangmengying in the Henan Province, it is reported that the rate of cancer infection is even more than the birth rate(CHEN 2020).

In Shenzhen city in the southern Guangdong province in China, the Maozhou River had attained notoriety for pollution. In 2019 , a total of 2.5 million tons of pollutants were removed from the river. Over a period the water colour in the towns and villages in its vicinity had changed from white to a shade of orange as a results of the impact of different forms of varying industrial effluent(Wang, Zhang et al. 2020). According to the Guangdong provincial administration, an accumulated amount of 120 billion RMB (about 16.9 billion U.S. dollars) were invested into the pollution treatment of these heavily-polluted rivers in Shenzhen and to enhance the landscape enhancement of its surrounding areas(Guo, Chen et al. 2020).

Scientific experiments have revealed the presence of contaminants such as cadmium and zinc which are known cancer causing chemicals in rivers across China. Shangba and Wengyuan cities in Guangdong province have gained notoriety for both Cadmium and Lead Pollution in rivers. For example, in Shangba, Guo, Chen et al. (2020) reports that the Lead in the soil was 44 times higher than normal and cadmium 12 times higher (1). Both Cadmium and Lead are well known for their being a human carcinogen. In 2017, a total number of fishes, chicken, ducks, animals and person that came in long contact with the river died(Guo, Chen et al. 2020). The 2019, State of Ecological and Environmental Report by China's Ministry of Ecology and Environment summarises some of the water pollution challenges and achievements. From this report, it is evident that continuous improvement of water and ocean quality remains a major priority in China's ecological civilisation and beautiful china dream due to its healthcare implications. In 2019 alone the Chinese government spent a total of 53.2 billion Yuan to promote an integrated water, air, soil and rural pollution management. The same year the national green development fund was established to sustain the program (State of Ecology \& Environment Report Review, 2019).

Page $7 / 19$ 


\section{Discussion}

Improving Air Pollution in China

Even though ambient air quality in China has improved significantly since the beginning of 2020, a number of researchers believe this is attributable to the outbreak of the novel coronavirus (COVID-19) in December 2019 (Muhammad, Long et al. 2020). With the onset of the virus, a number of economic activities especially factory work were suspended for the first three months of the year while a significant amount of other pollution-making activities have been reduced in China for most part of the year. This notwithstanding, air quality in China remains the worst in the world and its outdoor air pollution is has ramifying public health concerns(Ebrahimi, Khalili et al. 2020). In 2019, the World Bank estimated that the health cost associated with outdoor air quality in China alone is 350 billion Chinese Yuan but could reach 500 billion Chinese Yuan by 2025.

This is nearly $4 \%$ of China Gross Domestic Product. This assessment is based only on the healthcare expenditure directly traced to air pollution-related cardiopulmonary disease and easily traceable outpatient and emergency department visits (Ito and Zhang 2020). The estimated health - related cost also includes pollution-induced changes in respiratory and other clinical symptoms, lung function and poor immune function. As indicated by China's Environment Ministry, the problem is that several chemicals and heavy metals that are banned in other countries are still found in many parts of China due to their economic value. These have contributed to the emergence of cancer villages in individual regions, which is the first official admission of the existence of "cancer villages" that continues to plague China for decades (Li, Jin et al. 2019).

These challenges notwithstanding, China has made some persistent progress in the production of clean energy and this has become a global reference point of sustainable economic growth. The clean energy and other initiatives to reduce pollution has caught the attention of very affluent western countries to catch up with China but the clean energy targets and achievements in China have not come on a silver platter (Aunan, Hansen et al. 2019). On the contrary, it is the results of several years of planning and commitment unprecedented in the history of China. For example, in 2010, the NPC outline the major plan for the reorganisation of the energy sector to achieve higher conservation through new energy technologies, and environmental protection initiatives. The NPC devoted a substantial amount of $\$ 20$ billion U.S. dollars to be able to achieve this objective(Yang and Yang 2019).

Even though the initial cost of clean energy appears to be costly, it remains crucial to China's sustainable economic development due to the positive health effects relative to other types of non-renewable or unclean air(Hou, Chan et al. 2019). The long term accumulation of these negative externalities of unclean air can be more debilitating than the cost of clean air both in terms of out of pocket expenditure and loss of human capital that is needed to anchor China's economic development (Yang, Hao et al. 2020). Going forward, China must further limit the serious environmental externalities of fossil fuel dependence in some parts of the country especially in Lanzhou, Urumqi, Linfen cities etc.

Instead, it must keep the momentum to continue investing heavily to reduce reliance on coals and other fossil fuels which has received global applause over the last two years. In 2019, China invested twice as the US in clean energy technology (\$34.6 billion vs. \$18.6 billion), propelling it to the number one place in global ranking of clean energy investment(Zhang, Dong et al. 2020). This again places China neck-to-neck with the US to become on the top of the global rankings in total renewable energy production ( $52.5 \mathrm{GW}$ vs. $53.4 \mathrm{GW})$.

Despite the fact that China has invested nearly $100 \%$ more than the US in terms of clean energy, dirty energy has dominated its economy for such a long time, hence the massive investment in clean energy has only improved renewable energy percentage of the total energy use to $4 \%$ which is at par with the US (Dutheil, Baker et al. 2020). The competition between China and America in terms of the highest proportion of clean air is critical for the global economy since the two countries alone contributes half to poor air quality across the globe (Li, Jacob et al. 2019).

China must seize the opportunity of the US's withdrawal from the Paris Accord to consolidates its global environmental legitimacy and brand and consolidate environmental healthcare across. Between 2017 and 2019, China has increased its green energy capacity by nearly $79 \%$ as against the $24 \%$ increment in the US within the period (Tilt 2019). China's ability to pursue and achieve its ambitious renewable energy targets can go a long way to promote safer environment and sustainable economic development. For example the country hopes to generate $20 \mathrm{GW}$ from solar photovoltaics, $30 \mathrm{GW}$ from biomass, and a massive $150 \mathrm{GW}$ from wind by 2020 which appears to be beyond its reach considering the impact of COVID-19. These investments will be critical in promoting innovation in clean energy which is directly and significantly related to high environmental healthcare. However, these investments alone are not enough to guarantee China's global leadership in the development of clean energy technology and innovation(Gu, Cao et al. 2019). Thus for China to emerge as a leader in clean energy and other environmental technology areas, it must improve higher education in science and engineering, invest in infrastructure, fund research and development, and encourage indigenous entrepreneurship and inventive activity.

\section{Improving Water Pollution}

The new ecological and socio-economic aspirations of China are engraved in the opening statement of the report of the $18^{\text {th }}$ meeting of the China Communist Party. The statement affirms China's confidence about its future environmental quality. The statement reiterates China target to become a moderately prosperous society in all respect by 2021 when the CCP celebrates its centenary anniversary and become a modern prosperous, strong democratic, harmonious and culturally advanced socialist country by 2049 when China celebrates its centennial anniversary(Hou, Chan et al. 2019).

A key part of this agenda is to ensure that clean water is available to all citizens in fulfilment of both national and international obligations. The 2019, report of the State of Ecology \& Environment Report Review provides some progress in this regard and China must strengthen its effort to achieve the desired 
objectives. In China, water quality is graded on a scale of (I-V+).(Fang, Chen et al. 2019). Water sources with I- III water quality are considered fit for human use in ascending order. On the other hand Grade IV-V+ water sources are "unfit for human contact". The State of Ecology \& Environment Report Review (2019) reveals that shallow water and groundwater quality is still far from targets. As of $2019,85.7 \%$ of ground water even failed the lowest ground water quality test Grade IV and V categories (unfit for human contact). Only $14.4 \%$ matched the grade 1-5 category or fit for human use.

The situation is even worse in the case of shallow water because $46.2 \%$ fall below the Grade $V$ category which is classified as highly unfit for human contact. Comparatively, even though Grade I-III category of groundwater improved from $13.8 \%$ to $14.4 \%$ in 2019 , and $14 \%$ more of Grade V improved from to Grade V water quality levels, the gains were offset by the deterioration in the quantity of Grade $\mathrm{V}+$ groundwater from $15.5 \%$ to $18.8 \%$ which is below the $15 \%$ target by 2020 (State of Ecology \& Environment Report Review, 2019).

A major achievement for China between 2015 and 2019 is that while ground and shallow water quality continues to decline, the quality of national surface water has improved significantly since 2015 . Between 2015 and 2019 , Grade I-III national surface water quality improved from $64.5 \%$ to $74.9 \%$ in 2019 while Grade IV-V surface water category improved from $26.7 \%$ to $21.7 \%$. Grade V+ national surface water has consistently improved from $8.8 \%$ to $3.4 \%$ between 2015 and 2019(Cai, He et al. 2020).

The current statistics on the water quality in key lakes and reservoirs also provide some indication of the progress in the water pollution and the consequential effect on human health(Wang, Qi et al. 2020). Between 2015 and 2019, China has recorded year-on-year improvement in water quality of its key lakes and reservoirs. Most of them have attained Grade I-III. Statistically, Grade I-III water category of lakes and reservoirs moved from $66.6 \%$ in 2018 to $69.1 \%$ in 2019 but the number of grade V+ water quality in lakes and reservoirs has declined from 8.1\% in 2019 to $7.3 \%$ in 2019 (Qin, Pang et al. 2020).

Together, there are 110 key lakes and reservoirs in this category and more effort is needed to bring them to the desirable level if water pollution-related healthcare crisis is to subside in villages and rural communities in China where most of the effect of pollution is strongly felt on the healthcare of the inhabitants (Ahmed, Asghar et al. 2020)

A major part of China's effort to improve environmental health is to improve water quality in the 7 major rivers namely; Yangtze, Yellow, Pearl, Songhua, Huai, Liao, Hai rivers. The documents that details their priority for water quality is the Water Pollution and Prevention Control Law ("Water Ten Law") which was issued in 2015.. This document has set very tough targets on water pollution, prevention and control(Zhang, Hu et al. 2020). It has been promulgated as an umbrella plan that ties in all other key national policies for water scarcity and geographical mismatch in water quality distribution.

The Water Ten Law was finally approved in 2016 to become the legal backbone for the Water Ten Plan and came into force on 1 January 2018 . The law provides the legislative framework to guide discharge of key water pollutants and water quality improvement targets. The new law also means that environmental violations are going to face more severe punishments. The penalties for excessive pollutant discharge have been increased to RMB100,000 RMBmn, compared to 2 to 5 times the pollutant discharge fee previously(Xiao, Xiao et al. 2020)

Currently, the Yellow river is the only river in the northern part of China to meet the Ten Target of 70\% in Grade I-III water quality (Yang, Yao et al. 2020). Between 2015 and 2019, Grade I-III water quality in the Yellow river increased from $66.4 \%$ to $73 \%$ in 2019 . However the river still contains a lot of pollutants despite the improvement in water quality thus downgrading the Grade $5+$ water quality from $12.4 \%$ to $8.8 \%$. This falls short of Grade $V+$ target of less than $<5 \%$. The quality of water in the Yellow river is important to national health security as evidenced in the words of President Xi in March 2019 . This is because it is the main source of water for food and industry by nearly 150 million people living along its banks ).

To this extent China has put forward a special water restoration plan for the ecological protection and high quality development of the yellow river. The Supreme People's Court has vowed to punish criminal acts damaging the ecological environment in the Yellow River Basin(Qu, Wu et al. 2020). This notwithstanding, China's operational mechanism to map and monitor all sewerage outlets in the Yellow river to fight pollution requires strict supervision and implementation along this large river basin. China must apply the Yellow River Ecological Basin pilot scheme to protect and beautify the yellow river as well.

Water safety and its consequential environmental health effect is the reason why China is investing a lot of money to protect the Yangtze and Pear river basins to achieve water ten targets. These Grade I-III water quality from these two rivers located in the Southern China have consistently outperformed the rivers in northern China (Liu and Mao 2020). Indeed they are the only rivers in China that have met the water ten targets in terms of Grade I-III water quality, however, they also have the highest level of $\mathrm{V}+$ water supply. The need to protect the Yangtze from excessive pollution is largely because Yangtze has a lot of socio-economic importance to China.

This explains why the government has set a much higher water quality standard for the river since 2018. Through the legislation of the Yangtze Action Plan, Grade I-III water quality level in the Yangtze is expected to reach approximately $85 \%$ and Grade IV+ is predicted to be less than $2 \%$ by the end of 2020 (Zhang, Zhang et al. 2020). Some of the policies that have been implemented by government to effectively promote the agenda have yielded substantial benefits as the water quality has improved from 87.5 in 2018 to 91.7 in 2019 and Grade IV+ water has also improved from $1.8 \%$ to $0.6 \%$ - meeting both targets(Wen, Song et al. 2020)

In the case of the Pearl, Grade I-III water quality has not been stable. For example between 2017 and 2018, the water quality declined from $85.6 \%$ but in 2019 it has seen marginal improvement from $84.8 \%$ to $86.1 \%$. At the same time Grade $\mathrm{V}+$ water quality in the Pear River has also improved from $5.5 \%$ to $3 \%$. Despite these achievements, much still remains to be done, if China is to achieve high environmental protection of the Yangtze and the Pearl River Delta to provide sustainable quality water for the citizens along its banks (Liu, Li et al. 2020). This is because the success is attenuated by the persistent decline in the water quality along the tributaries of the Pearl River. 
For example, the persistent dumping of dye and other dangerous chemicals may erode all the gains been made in other areas of the rivers; protection. The governed must expedite action to review both the Yangtze River Protection Act and the Pearl River Delta Ecological Protection. Even though the Standing Committee of the National People Congress has indicated its willingness to review these documents, it's long overdue and extra effort to ensure quick review and legislation can compensate for past lapses (Ruan, Zhuang et al. 2020).

The protection of the Songhua River and the Huai River requires substantial investment to improve clean water availability from them since they are part of the top seven important rivers in China. According to Wang (Wang, Zhang et al. 2020) both the quantity of poor water (Grade V+) in both the Huai and Songhua Rivers reached $2.8 \%$ and Hua $0.6 \%$ respectively. However, the two rivers have not been able to improve on the percentage of Grade 1 -III levels to the estimated $70 \%$ in the Ten Water Target. In 2018, Grade I-III water quality in Songhua River declined $57.9 \%$ to $66.4 \%$ which still falls short of the $70 \%$ benchmark. In the case of the Huai River, the percentage of Grade I-III water quality benchmark is still unmet since due to marginal the marginal improvement from $57.2 \%$ to 63.7\% in 2019 (State of Ecology \& Environment Report Review, 2019). This implies that currently the Huai and Yangtze rivers have the lowest Grade V+ water quality category performance at $0.6 \%$. The grade I-III water quality in the Liao River has improved from $48.9 \%$ in 2018 to $56.3 \%$ in 2019 whereas that of the Hai river has improved from $46.3 \%$ in 2018 to $51.9 \%$ in 2019 . Similarly the Grade IV+ water quality in the Liao River has also improved from $22.1 \%$ to $8.7 \%$.

\section{Conclusion}

The objective of this research was to systematically explore China's progress in air and water pollution as part of its ecological civilisation and beautiful China dream. The environmental healthcare implications of the persistence and improvement to environmental pollution were of significant interest in this research. In 2018, China's ecological civilisation and the beautiful China dream were ultimately engraved into the national ideology for socio-economic and political development and national orientation. At the heart of this dream is the need to rejuvenate and modernise the Chinese nation through sustainable development. However, the path to economic prosperity has not been all rosy in terms of the environmental pollution and the contemporaneous health impact on its citizens and beyond.

The extant literature is replete with studies that highlight China's high percentage contribution to global pollution. For this reason China is rarely a leading source of inspiration for successful environment management. For many years, it has tolerated compromised environmental standards that have culminated into endemic air, water, soil quality that continues to plague many of its cities. In cities such as Qingtai, Linfen, Lanzhou and Urumqi, pollutions have long exceeded the global allowable limits and several villages under them have been declared as cancer villages. Further, China's Ministry of Environmental Protection which is the top environmental regulator has over the years classified more than half of its water resources as too polluted for human use.

Moreover, for the first time, China has acknowledged that cancer villages exit. These are villages where pollution levels have reached unsustainable levels such that entire whole communities stand the risk. This represented the saddest commentary of an otherwise economic renaissance or turnaround that has left several critics of its political and economic orientation dumbfounded. Despite the persisting challenges, it appears that the Chinese government has abandoned its perceived obdurate approach to environmental pollution as suggested by western countries and researchers. This posture fuelled speculation that China prioritises economic development at any cost, even at the health of its citizens and wholesale eco-destruction. Over the last decade however, China has acknowledged the daunting environmental challenges facing the country and has rejuvenated its effort to overcome these challenges especially water and air pollution.

Currently China, strategy is tailored towards a move away from coal based economy to clean energy. Since 2005 , China has invested in clean energy than any other country in the world. The 2019, State of Ecology \& Environment Report Review shows that China can become a beacon of clean energy and an inspiration to even developed countries. There is the need to double its effort to arrest water pollution. The benefit of most of ecological reclamation strategies that have been put in place currently remains a work in progress in China hence the need to strengthen surveillance especially among industries that pollute these water bodies. The Yangtze Action Plan and "Yangtze River Protection Act or the, Water Resource Special Plan for Ecological Protection and High Quality Development of the Yellow River must be extended to all other strategic national rivers including the local levels to ensure effective protection of their basins. There is the need to review the pollution violation fine upwards in order to improve compliance of the private sector and other individuals whose actions and inactions compromise the quality of environmental health that must be a public good for all citizens

\section{Declarations}

\section{ACKNOWLEDGEMENT}

National Natural Science Foundation of China (71904066), the Social science application research project of Jiangsu Province (19SYB-095) and the Universities' Philosophy and Social Science Researches in Jiangsu Province (2019SJA1884)

\section{CONFLICT OF INTEREST}

The authors declare that there is no conflict of interest among them.

\section{ETHICAL APPROVAL}

This article does not require any human/animal subjects to acquire such approval.

\section{ACKNOWLEDGEMENT}


National Natural Science Foundation of China (71904066), the Social science application research project of Jiangsu Province (19SYB-095) and the Universities' Philosophy and Social Science Researches in Jiangsu Province (2019SJA1884)

\section{CONFLICT OF INTEREST}

The author declares that there is no conflict of interest to declare.

\section{ETHICAL APPROVAL}

This article does not require any human/animal subjects to acquire such approval.

\section{References}

Ahmed, Z., M. M. Asghar, M. N. Malik and K. Nawaz (2020). "Moving towards a sustainable environment: The dynamic linkage between natural resources, human capital, urbanization, economic growth, and ecological footprint in China." Resources Policy. 67: 101677.

Aunan, K., M. H. Hansen, Z. Liu and S. Wang (2019). "The hidden hazard of household air pollution in rural China." Environmental Science \& Policy $93: 27-33$. Baranovitch, N. (2019). "The Impact of Environmental Pollution on Ethnic Unrest in Xinjiang: A Uyghur Perspective." Modern China 45(5): 504-536.

Bian, Y., K. Song and J. Bai (2019). "Market segmentation, resource misallocation and environmental pollution." Journal of Cleaner Production 228: $376-387$. Cai, J., Y. He, R. Xie and Y. Liu (2020). "A footprint-based water security assessment: an analysis of Hunan province in China." Journal of Cleaner Production 245: 118485 .

CHEN, A. (2020). CHINESE CANCER VILLAGES: Rural Development, Environmental Change and Public Healthrural... Development, Environmental Change and Public Healt, AMSTERDAM University Press.

Chen, J., J. Lu, J. Ning, Y. Yan, S. Li and L. Zhou (2019). "Pollution characteristics, sources, and risk assessment of heavy metals and perfluorinated compounds in PM 2.5 in the major industrial city of northern Xinjiang, China." Air Quality, Atmosphere \& Health 12(8): 909-918.

Cui, C., H. Dong, H. Ren, G. Lin and L. Zhao (2020). "Characterization of Esophageal Cancer and Its Association with Influencing Factors in Guangzhou City, China." International journal of environmental research and public health 17(5): 1498.

Dutheil, F., J. S. Baker and V. Navel (2020). "COVID-19 as a factor influencing air pollution?" Environmental Pollution (Barking, Essex: 1987). $263:$ 114466.

Ebrahimi, M., N. Khalili, S. Razi, M. Keshavarz-Fathi, N. Khalili and N. Rezaei (2020). "Effects of lead and cadmium on the immune system and cancer progression." Journal of Environmental Health Science and Engineering: 1-9.

Fan, Y., K. Zheng, Z. Zhu, G. Chen and X. Peng (2019). "Distribution, sedimentary record, and persistence of microplastics in the Pearl River catchment, China." Environmental Pollution 251: 862-870.

Fang, D., B. Chen, K. Hubacek, R. Ni, L. Chen, K. Feng and J. Lin (2019). "Clean air for some: Unintended spillover effects of regional air pollution policies." Science advances 5(4): eaav4707.

Feng, X., L. Shao, C. Xi, T. Jones, D. Zhang and K. BéruBé (2020). "Particle-induced oxidative damage by indoor size-segregated particulate matter from coalburning homes in the Xuanwei lung cancer epidemic area, Yunnan Province, China." Chemosphere: 127058.

Gao, Y., S. Shahab and N. Ahmadpoor (2020). "Morphology of Urban Villages in China: A Case Study of Dayuan Village in Guangzhou." Urban Science 4(2): 23. Gu, H., Y. Cao, E. Elahi and S. K. Jha (2019). "Human health damages related to air pollution in China." Environmental Science and Pollution Research 26(13): 13115-13125.

Guo, C., Y. Chen, W. Xia, X. Qu, H. Yuan, S. Xie and L.-S. Lin (2020). "Eutrophication and heavy metal pollution patterns in the water suppling lakes of China's south-to-north water diversion project." Science of The Total Environment 711: 134543.

Guo, J., X. Zhang, F. Gu, H. Zhang and Y. Fan (2020). "Does air pollution stimulate electric vehicle sales? Empirical evidence from twenty major cities in China." Journal of Cleaner Production 249: 119372.

Hao, Y., Y. Guo, Y. Guo, H. Wu and S. Ren (2020). "Does outward foreign direct investment (OFDI) affect the home country's environmental quality? The case of China." Structural Change and Economic Dynamics 52: 109-119.

He, J., H. Liu and A. Salvo (2019). "Severe air pollution and labor productivity: Evidence from industrial towns in China." American Economic Journal: Applied Economics 11(1): 173-201.

He, L., H. Zhong, G. Liu, Z. Dai, P. C. Brookes and J. Xu (2019). "Remediation of heavy metal contaminated soils by biochar: Mechanisms, potential risks and applications in China." Environmental pollution 252: 846-855. 
He, X. and P. Li (2020). "Surface water pollution in the middle Chinese Loess Plateau with special focus on hexavalent chromium (Cr 6+): occurrence, sources and health risks." Exposure and Health: 1-17.

Hou, X., C. Chan, G. Dong and S. Yim (2019). "Impacts of transboundary air pollution and local emissions on PM2. 5 pollution in the Pearl River Delta region of China and the public health, and the policy implications." Environmental Research Letters 14(3): 034005.

Ito, K. and S. Zhang (2020). "Willingness to pay for clean air: Evidence from air purifier markets in China." Journal of Political Economy 128(5): 1627-1672.

Jiang, Y., S. Chen, B. Hu, Y. Zhou, Z. Liang, X. Jia, M. Huang, J. Wei and Z. Shi (2020). "A comprehensive framework for assessing the impact of potential agricultural pollution on grain security and human health in economically developed areas." Environmental Pollution: 114653.

Li, J., H. Liao, J. Hu and N. Li (2019). "Severe particulate pollution days in China during 2013-2018 and the associated typical weather patterns in BeijingTianjin-Hebei and the Yangtze River Delta regions." Environmental Pollution 248: 74-81.

Li, K., L. Fang and L. He (2019). "How population and energy price affect China's environmental pollution?" Energy_policy 129: $386-396$.

Li, K., D. J. Jacob, H. Liao, J. Zhu, V. Shah, L. Shen, K. H. Bates, Q. Zhang and S. Zhai (2019). "A two-pollutant strategy for improving ozone and particulate air quality in China." Nature Geoscience 12(11): 906-910.

Li, R., Z. Wang, L. Cui, H. Fu, L. Zhang, L. Kong, W. Chen and J. Chen (2019). "Air pollution characteristics in China during 2015-2016: Spatiotemporal variations and key meteorological factors." Science of the total environment 648: 902-915.

Li, X., X.-M. Hu, Y. Ma, Y. Wang, L. Li and Z. Zhao (2019). "Impact of planetary boundary layer structure on the formation and evolution of air-pollution episodes in Shenyang, Northeast China." Atmospheric Environment 214: 116850.

Li, X., L. Jin and H. Kan (2019). Air pollution: a global problem needs local fixes, Nature Publishing Group.

Li, Y., Y. Fu, K. Hu, Y. Zhang, J. Chen, S. Zhang, B. Zhang and Y. Liu (2020). "Positive correlation between human exposure to organophosphate esters and gastrointestinal cancer in patients from Wuhan, China." Ecotoxicology and Environmental Safety. 196: 110548.

Li, Y., J. Huang, Z. Li and K. Zheng (2020). "Atmospheric pollution revealed by trace elements in recent snow from the central to the northern Tibetan Plateau." Environmental Pollution: 114459.

Liang, D., Y.-q. Wang, Y.-j. Wang and C. Ma (2019). "National air pollution distribution in China and related geographic, gaseous pollutant, and socio-economic factors." Environmental Pollution 250: 998-1009.

Liang, L., Z. Wang and J. Li (2019). "The effect of urbanization on environmental pollution in rapidly developing urban agglomerations." Journal of Cleaner Production 237: 117649.

Liang, W. and M. Yang (2019). "Urbanization, economic growth and environmental pollution: Evidence from China." Sustainable Computing: Informatics and Systems 21: 1-9.

Liao, Q., W. Jin, Y. Tao, J. Qu, Y. Li and Y. Niu (2020). "Health and Economic Loss Assessment of PM2. 5 Pollution during 2015-2017 in Gansu Province, China." International Journal of Environmental Research and Public Health 17(9): 3253.

Lin, S.-S., S.-L. Shen, A. Zhou and H.-M. Lyu (2020). "Sustainable development and environmental restoration in Lake Erhai, China." Journal of Cleaner Production: 120758.

Liu, H., Y. Zhang, Y. Tian, Y. Zheng, F. Gou, X. Yang, J. He, X. Liu, L. Meng and W. Hu (2020). "Epidemic features of seasonal influenza transmission among eight different climate zones in Gansu, China." Environmental Research 183: 109189.

Liu, J., G. Kiesewetter, Z. Klimont, J. Cofala, C. Heyes, W. Schöpp, T. Zhu, G. Cao, A. G. Sanabria and R. Sander (2019). "Mitigation pathways of air pollution from residential emissions in the Beijing-Tianjin-Hebei region in China." Environment international 125: 236-244.

Liu, K. and B. Lin (2019). "Research on influencing factors of environmental pollution in China: A spatial econometric analysis." Journal of cleaner production 206: 356-364.

Liu, S., Y. Liu, D. Yang, C. Li, Y. Zhao, H. Ma, X. Luo and S. Lu (2020). "Trace elements in shellfish from Shenzhen, China: Implication of coastal water pollution and human exposure." Environmental Pollution: 114582.

Liu, Y., H. Li, G. Cui and Y. Cao (2020). "Water quality attribution and simulation of non-point source pollution load flux in the Hulan River basin." Scientific Reports 10(1): 1-15.

Liu, Y. and D. Mao (2020). "Integrated assessment of water quality characteristics and ecological compensation in the Xiangjiang River, south-central China." Ecological Indicators 110: 105922.

Liu, Z., J. Zhou, J. Zhang, Y. Mao, X. Huang and G. Qian (2020). "Evaluation for the heavy metal risk in fine particulate matter from the perspective of urban energy and industrial structure in China: A meta-analysis." Journal of Cleaner Production 244: 118597.

Page 12/19 
Ma, T., S. Sun, G. Fu, J. W. Hall, Y. Ni, L. He, J. Yi, N. Zhao, Y. Du and T. Pei (2020). "Pollution exacerbates China's water scarcity and its regional inequality." Nature Communications 11 .

Ma, T., N. Zhao, Y. Ni, J. Yi, J. P. Wilson, L. He, Y. Du, T. Pei, C. Zhou and C. Song (2020). "China's improving inland surface water quality since 2003." Science advances 6(1): eaau3798.

Ma, X., H. Jia, T. Sha, J. An and R. Tian (2019). "Spatial and seasonal characteristics of particulate matter and gaseous pollution in China: Implications for control policy." Environmental Pollution 248: 421-428.

Ma, Y., B. Ma, H. Jiao, Y. Zhang, J. Xin and Z. Yu (2020). "An analysis of the effects of weather and air pollution on tropospheric ozone using a generalized additive model in Western China: Lanzhou, Gansu." Atmospheric Environment 224: 117342.

Ma, Z., R. Liu, Y. Liu and J. Bi (2019). "Effects of air pollution control policies on PM 2.5 pollution improvement in China from 2005 to 2017 : a satellite-based perspective." Atmospheric Chemistry and Physics 19(10): 6861-6877.

Mohsen, M., Q. Wang, L. Zhang, L. Sun, C. Lin and H. Yang (2019). "Microplastic ingestion by the farmed sea cucumber Apostichopus japonicus in China." Environmental Pollution 245: 1071-1078.

Muhammad, S., X. Long and M. Salman (2020). "COVID-19 pandemic and environmental pollution: a blessing in disguise?" Science of The Total Environment: 138820

Peng, L., X. Zhao, Y. Tao, S. Mi, J. Huang and Q. Zhang (2020). "The effects of air pollution and meteorological factors on measles cases in Lanzhou, China." Environmental Science and Pollution Research: 1-10.

Qin, L.-T., X.-R. Pang, H.-H. Zeng, Y.-P. Liang, L.-Y. Mo, D.-Q. Wang and J.-F. Dai (2020). "Ecological and human health risk of sulfonamides in surface water and groundwater of Huixian karst wetland in Guilin, China." Science of The Total Environment 708: 134552.

Qu, S., W. Wu, W. Nel and J. Ji (2020). "The behavior of metals/metalloids during natural weathering: A systematic study of the mono-lithological watersheds in the upper Pearl River Basin, China." Science of The Total Environment 708: 134572.

Ruan, S., Y. Zhuang, S. Hong, L. Zhang, Z. Wang, X. Tang and W. Wen (2020). "Cooperative identification for critical periods and critical source areas of nonpoint source pollution in a typical watershed in China." Environmental Science and Pollution Research: 1-12.

Sierra-Hernández, M. R., E. Beaudon, P. Gabrielli and L. Thompson (2019). "21st-century Asian air pollution impacts glacier in northwestern Tibet." Atmospheric Chemistry \& Physics 19(24).

Sun, X., X. Peng and R. Hou (2020). Metrological study on the literature of regional distribution of esophageal cancer in China. AIP Conference Proceedings, AIP Publishing LLC.

Tan, H., L. Yang, Y. Yu, Q. Guan, X. Liu, L. Li and D. Chen (2019). "Co-existence of organophosphate di-and tri-esters in house dust from South China and Midwestern United States: implications for human exposure." Environmental science \& technology 53(9): 4784-4793.

Tilt, B. (2019). "China's air pollution crisis: Science and policy perspectives." Environmental Science \& Policy. 92: 275-280.

Wang, J. and Y. Song (2020). "Effect of water pollution control on provincial boundaries of River-Director System: based on the study of the Yangtze River valley in China." Environmental Science and Pollution Research: 1-11.

Wang, M. H., Y. He and B. Sen (2019). "Research and management of plastic pollution in coastal environments of China." Environmental Pollution 248: 898905.

Wang, P., Y. Hu and H. Cheng (2019). "Municipal solid waste (MSW) incineration fly ash as an important source of heavy metal pollution in China." Environmental pollution 252: 461-475.

Wang, R., R. Qi, J. Cheng, Y. Zhu and P. Lu (2020). "The behavior and cognition of ecological civilization among Chinese university students." Journal of Cleaner Production 243: 118464.

Wang, S., C. Zhang, Z. Pan, D. Sun, A. Zhou, S. Xie, J. Wang and J. Zou (2020). "Microplastics in wild freshwater fish of different feeding habits from Beijiang and Pearl River Delta regions, south China." Chemosphere: 127345.

Wang, Y. and G. Zhu (2020). "Risk associated with increasing bromide in drinking water sources in Yancheng City, China." Environmental Monitoring and Assessment 192(1): 36.

Wen, Z., K. Song, G. Liu, L. Lyu, Y. Shang, C. Fang and J. Du (2020). "Characterizing DOC sources in China's Haihe River basin using spectroscopy and stable carbon isotopes." Environmental Pollution 258: 113684.

Xiao, Y., Q. Xiao and X. Sun (2020). "ecological Risks Arising from the Impact of Large-scale Afforestation on the Regional Water Supply Balance in Southwest china." Scientific Reports 10(1): 1-10. 
Xu, W., J. Sun, Y. Liu, Y. Xiao, Y. Tian, B. Zhao and X. Zhang (2019). "Spatiotemporal variation and socioeconomic drivers of air pollution in China during 20052016." Journal of environmental management 245: 66-75.

Yang, T., Y. Liu, W. Zhao, Z. Chen and J. Deng (2020). "Association of Ambient Air Pollution with Nasopharyngeal Carcinoma Incidence in Ten Large Chinese Cities, 2006-2013." International Journal of Environmental Research and Public Health 17(6): 1824.

Yang, W., G. Yuan and J. Han (2019). "Is China's air pollution control policy effective? Evidence from Yangtze River Delta cities." Journal of Cleaner Production 220: $110-133$.

Yang, X., S. Lin, Y. Li and M. He (2019). "Can high-speed rail reduce environmental pollution? Evidence from China." Journal of Cleaner Production 239: 118135.

Yang, Y. and W. Yang (2019). "Does whistleblowing work for air pollution control in China? A study based on three-party evolutionary game model under incomplete information." Sustainability. 11(2): 324.

Yang, Y., C. Yao and D. Xu (2020). "Ecological compensation standards of national scenic spots in western China: A case study of Taibai Mountain." Tourism Management 76: 103950.

Yang, Z., J. Hao, S. Huang, W. Yang, Z. Zhu, L. Tian, Y. Lu, H. Xiang and S. Liu (2020). "Acute effects of air pollution on the incidence of hand, foot, and mouth disease in Wuhan, China." Atmospheric Environment 225: 117358.

Yongjian, Z., X. Jingu, H. Fengming and C. Liqing (2020). "Association between short-term exposure to air pollution and COVID-19 infection: Evidence from China." Science of the total environment: 138704.

Yu, M., Y. Zhu, C.-J. Lin, S. Wang, J. Xing, C. Jang, J. Huang, J. Huang, J. Jin and L. Yu (2019). "Effects of air pollution control measures on air quality improvement in Guangzhou, China." Journal of environmental management 244: 127-137.

Yu, Y., X. Yang and K. Li (2019). "Effects of the terms and characteristics of cadres on environmental pollution: evidence from 230 cities in China." Journal of environmental management 232: 179-187.

Zeng, Y., Y. Cao, X. Qiao, B. C. Seyler and Y. Tang (2019). "Air pollution reduction in China: Recent success but great challenge for the future." Science of the Total Environment 663: 329-337.

Zhang, B., Q.-Q. Zhang, S.-X. Zhang, C. Xing and G.-G. Ying (2020). "Emission estimation and fate modelling of three typical pesticides in Dongjiang River basin, China." Environmental Pollution 258: 113660.

Zhang, C., H. Zhou, Y. Cui, C. Wang, Y. Li and D. Zhang (2019). "Microplastics in offshore sediment in the yellow Sea and east China Sea, China." Environmental Pollution 244: 827-833.

Zhang, H., H. Dong, M. Ren, Q. Liang, X. Shen, Q. Wang, L. Yu, H. Lin, Q. Luo and W. Chen (2020). "Ambient air pollution exposure and gestational diabetes mellitus in Guangzhou, China: A prospective cohort study." Science of the Total Environment 699: 134390.

Zhang, H., L. Wang, Y. Wang and S. Chang (2020). "Using disability-adjusted life years to estimate the cancer risks of low-level arsenic in drinking water." Journal of Environmental Science and Health, Part A 55(1): 63-70.

Zhang, J.-Y., T.-T. Gong, Y.-H. Huang, J. Li, S. Liu, Y.-L. Chen, L.-L. Li, C.-Z. Jiang, Z.-J. Chen and Q.-J. Wu (2020). "Association between maternal exposure to PM10 and polydactyly and syndactyly: a population-based case-control study in Liaoning Province, China." Environmental Research: 109643.

Zhang, Y., Y. Hu, B. Zhang, Y. Li, X. Zhang and Y. Xie (2020). "Conflict between nature reserves and surrounding communities in China: An empirical study based on a social and ecological system framework." Global Ecology and Conservation 21: e00804.

Zhao, H., G. Geng, Q. Zhang, S. J. Davis, X. Li, Y. Liu, L. Peng, M. Li, B. Zheng and H. Huo (2019). "Inequality of household consumption and air pollution-related deaths in China." Nature communications 10(1): 1-9.

Zheng, S., J. Wang, C. Sun, X. Zhang and M. E. Kahn (2019). "Air pollution lowers Chinese urbanites' expressed happiness on social media." Nature Human Behaviour 3(3): 237-243.

Zheng, Y., J. Peng, J. Xiao, P. Su and S. Li (2020). "Industrial structure transformation and provincial heterogeneity characteristics evolution of air pollution: Evidence of a threshold effect from China." Atmospheric Pollution Research 11(3): 598-609.

Zou, B., J. You, Y. Lin, X. Duan, X. Zhao, X. Fang, M. J. Campen and S. Li (2019). "Air pollution intervention and life-saving effect in China." Environment international 125: 529-541.

\section{Tables}


Table 1: Description of Studies

\begin{tabular}{|c|c|c|c|c|}
\hline Study & $\begin{array}{l}\text { Year of } \\
\text { Publication }\end{array}$ & Setting & $\begin{array}{l}\text { Focus of } \\
\text { Pollution }\end{array}$ & Key Findings \\
\hline Tan et al & 2019 & South China & Air & Co-existence of organophosphate di-and tri-esters \\
\hline Yu et al & 2019 & 230 Cities in China & Pollution & Characteristics of cadres on environmental pollution \\
\hline Zhang et al & 2019 & yellow Sea and east China Sea & Water & Microplastics in offshore sediment \\
\hline Yang et al & 2019 & Yangtze River Delta cities & Air & China's air pollution control policy \\
\hline Peng et al & 2019 & Lanzhou & Air & Air pollution and meteorological factors on measles cases \\
\hline Zhao et al & 2019 & China & Air & Household consumption and air pollution-related deaths \\
\hline Guo et al & 2019 & 20 major cities in China & Air & air pollution stimulate electric vehicle sales \\
\hline Liu et al & 2019 & Beijing-Tianjin-Hebei region & Air & $\begin{array}{l}\text { Mitigation pathways of air pollution from residential } \\
\text { emissions }\end{array}$ \\
\hline Zheng et al & 2019 & Urban China & Air & Air pollution and happiness on social media \\
\hline Yu et al & 2019 & Guangzhou & Air & Air pollution control measures \\
\hline Li et al & 2019 & Sheyang & Air & $\begin{array}{l}\text { Planetary boundary layer structure on the formation and } \\
\text { evolution of air-pollution }\end{array}$ \\
\hline Li et al & 2019 & Tibetan Plateau & Air & Atmospheric pollution \\
\hline Chen et al & 2019 & Xinjiang & Water & Heavy metals and perfluorinated compounds in Pollution \\
\hline Ma et al & 2019 & Lanzhou & Water & Weather and air pollution on tropospheric ozone \\
\hline Liao et al & 2019 & Gansu & Pollution & Health and Economic Loss Assessment of PM2. 5 Pollution \\
\hline Liu et al & 2020 & Gansu & Climate & Climate zones and seasonal epidemic \\
\hline Zhang et al & 2020 & Liaoning & Water & $\begin{array}{l}\text { Association between maternal exposure to PM10 and } \\
\text { polydactyly and syndactyly }\end{array}$ \\
\hline Yang et al & 2020 & 10 Cities in China & Air & $\begin{array}{l}\text { Ambient Air Pollution with Nasopharyngeal Carcinoma } \\
\text { Incidence }\end{array}$ \\
\hline Li et al & 2020 & $\begin{array}{l}\text { Beijing-Tianjin-Hebei/Yangtze River } \\
\text { Delta regions }\end{array}$ & Air & Particulate pollution days and weather paterns \\
\hline Fan et al & 2020 & Pearl River Delta & Water & $\begin{array}{l}\text { Distribution, sedimentary record, and persistence of } \\
\text { microplastics }\end{array}$ \\
\hline $\mathrm{He}$ and $\mathrm{Li}$ & 2020 & middle Chinese Loess Plateau & Water & Surface water pollution \\
\hline $\begin{array}{l}\text { Wang and } Y \text {. } \\
\text { Song }\end{array}$ & 2020 & Yangtze River valley & Water & Water pollution control on provincial boundaries \\
\hline Lin et al & 2020 & Lake Erhai & Water & Environmental restoration \\
\hline Li et al & 2020 & Wuhan & Water & Organophosphate esters and gastrointestinal cancer \\
\hline Feng et al & 2020 & Yunnan Province & Air & Coal-burning pollution and Lung Cancer \\
\hline $\begin{array}{l}\text { Wang and G. } \\
\text { Zhu }\end{array}$ & 2020 & Yancheng City & Water & Bromide in drinking water \\
\hline Cui et al & 2020 & Guangzhou & Water & Esophageal Cancer \\
\hline Liu et al & 2020 & Shenzhen & Water & Coastal water pollution and human exposure \\
\hline Shi et al & 2020 & 30 Provinces in China & Water & Water Pollution Emissions on Public Health \\
\hline Gao et al & 2020 & Dayuan Village in Guangzhou & Pollution & Pollution in Villages \\
\hline Wang et al & 2020 & $\begin{array}{l}\text { Beijiang and Pearl River Delta } \\
\text { regions }\end{array}$ & Water & Microplastics in wild freshwater fish \\
\hline Guo et al & 2020 & South to North China & Water & Heavy metal pollution patterns in the water \\
\hline Hou et al & 2020 & Pearl River Delta region & Air & Air pollution and local emissions \\
\hline Yang et al & 2020 & Wuhan & Air & $\begin{array}{l}\text { Air pollution on the incidence of hand, foot, and mouth } \\
\text { disease }\end{array}$ \\
\hline Zhang et al & 2020 & Guangzhou & Air & $\begin{array}{l}\text { Ambient air pollution exposure and gestational diabetes } \\
\text { mellitus }\end{array}$ \\
\hline
\end{tabular}




\begin{tabular}{|c|c|c|c|c|}
\hline Cai et al & 2020 & Hunan & Water & Footprint-based water security assessment \\
\hline Qin et al & 2020 & Guilin & Water & Sulfonamides in surface water and groundwater \\
\hline Xiao et al & 2020 & South West China & Water & $\begin{array}{l}\text { Large-scale Afforestation on the Regional Water Supply } \\
\text { Balance }\end{array}$ \\
\hline Yang et al & 2020 & Taibai Mountain-Western China & Pollution & Ecological Compensation \\
\hline Qu et al & 2020 & upper Pearl River Basin & Water & Behavior of metals/metalloids during natural weathering \\
\hline $\begin{array}{l}\text { Liu and D. } \\
\text { Mao, }\end{array}$ & 2020 & $\begin{array}{l}\text { Xiangjiang River, south-central } \\
\text { China }\end{array}$ & Water & Water quality characteristics and ecological compensation \\
\hline Zhang et al & 2020 & Dongjiang River basin & Water & Emission estimation and fate modelling \\
\hline Wen et al & 2020 & Haihe River basin & Water & Characterizing DOC sources in China \\
\hline Liu et al & 2020 & Hulan River basin & Water & Water quality attribution \\
\hline
\end{tabular}




\section{Table 2: Mixed Methods Appraisal Tool (MMAT) Study Quality Evaluation Schedule}

\begin{tabular}{|c|c|c|c|c|c|c|c|c|c|c|c|c|c|c|c|c|c|}
\hline Parameters & $\begin{array}{l}\text { Tan } \\
\text { et al }\end{array}$ & $\begin{array}{l}\text { Yu } \\
\text { et al }\end{array}$ & $\begin{array}{l}\text { Zhang } \\
\text { et al }\end{array}$ & $\begin{array}{l}\text { Yang } \\
\text { et al }\end{array}$ & $\begin{array}{l}\text { Peng } \\
\text { et al }\end{array}$ & $\begin{array}{l}\text { Zhao } \\
\text { et al }\end{array}$ & $\begin{array}{l}\text { Guo } \\
\text { et al }\end{array}$ & $\begin{array}{l}\text { Liu } \\
\text { et al }\end{array}$ & $\begin{array}{l}\text { Zheng } \\
\text { et al }\end{array}$ & $\begin{array}{l}\text { Yu } \\
\text { et al }\end{array}$ & $\begin{array}{l}\text { Li et } \\
\text { al }\end{array}$ & $\begin{array}{l}\text { Li et } \\
\text { al }\end{array}$ & $\begin{array}{l}\text { Chen } \\
\text { et al }\end{array}$ & $\begin{array}{l}\text { Ma } \\
\text { et al }\end{array}$ & $\begin{array}{l}\text { Liao } \\
\text { et al }\end{array}$ & $\begin{array}{l}\text { Liu } \\
\text { et al }\end{array}$ & $\begin{array}{l}Z \\
\text { et }\end{array}$ \\
\hline $\begin{array}{l}\text { Data sources } \\
\text { relevant? }\end{array}$ & $Y$ & Y & $Y$ & $\mathrm{Y}$ & Y & $Y$ & Y & $Y$ & Y & $\mathrm{Y}$ & $Y$ & Y & Y & $Y$ & $Y$ & $Y$ & $Y$ \\
\hline $\begin{array}{l}\text { Data analysis } \\
\text { process } \\
\text { relevant? }\end{array}$ & $Y$ & $Y$ & $Y$ & $\mathrm{Y}$ & Y & $Y$ & Y & $Y$ & Y & $Y$ & $\mathrm{Y}$ & $Y$ & Y & $Y$ & $\mathrm{Y}$ & $\mathrm{N}$ & $Y$ \\
\hline $\begin{array}{l}\text { Findings relate } \\
\text { to context? }\end{array}$ & $Y$ & Y & $Y$ & $\mathrm{~N}$ & Y & Y & Y & $Y$ & Y & $Y$ & $\mathrm{Y}$ & Y & Y & $\mathrm{Y}$ & $\mathrm{Y}$ & $Y$ & $\mathrm{Y}$ \\
\hline $\begin{array}{l}\text { Findings relate } \\
\text { to researchers' } \\
\text { influence? }\end{array}$ & $\mathrm{N}$ & $\mathrm{N}$ & $\mathrm{N}$ & $\mathrm{N}$ & Y & $\mathrm{N}$ & $\mathrm{N}$ & $\mathrm{N}$ & $\mathrm{N}$ & $\mathrm{N}$ & $\mathrm{N}$ & $\mathrm{N}$ & $\mathrm{N}$ & $\mathrm{N}$ & $\mathrm{N}$ & $\mathrm{N}$ & $\mathrm{N}$ \\
\hline $\begin{array}{l}\text { Clear description } \\
\text { of the sampling } \\
\text { process of } \\
\text { respondents }\end{array}$ & $\mathrm{Y}$ & Y & $\mathrm{Y}$ & $\mathrm{Y}$ & Y & $\mathrm{Y}$ & Y & $\mathrm{Y}$ & $\mathrm{Y}$ & $\mathrm{Y}$ & $\mathrm{Y}$ & Y & Y & $\mathrm{Y}$ & Y & $\mathrm{N}$ & $\mathrm{Y}$ \\
\hline \multirow{3}{*}{$\begin{array}{l}\text { Support from } \\
\text { funding } \\
\text { agencies }\end{array}$} & $\mathrm{N}$ & $\mathrm{N}$ & $\mathrm{N}$ & $\mathrm{N}$ & $\mathrm{N}$ & $\mathrm{N}$ & $\mathrm{N}$ & $\mathrm{N}$ & $\mathrm{N}$ & $\mathrm{N}$ & $\mathrm{N}$ & $\mathrm{N}$ & $\mathrm{N}$ & $\mathrm{N}$ & $\mathrm{N}$ & $\mathrm{N}$ & $\mathrm{N}$ \\
\hline & $67 \%$ & $67 \%$ & $67 \%$ & $50 \%$ & $83 \%$ & $67 \%$ & $67 \%$ & $67 \%$ & $50 \%$ & $67 \%$ & $67 \%$ & $67 \%$ & $67 \%$ & $67 \%$ & $67 \%$ & $33 \%$ & 6 \\
\hline & $\begin{array}{l}\text { Lin } \\
\text { et al }\end{array}$ & $\begin{array}{l}\text { Li et } \\
\text { al }\end{array}$ & $\begin{array}{l}\text { Feng } \\
\text { et al }\end{array}$ & $\begin{array}{l}\text { Wang } \\
\text { and } \\
\text { G. } \\
\text { Zhu }\end{array}$ & $\begin{array}{l}\text { Cui } \\
\text { et al }\end{array}$ & $\begin{array}{l}\text { Liu } \\
\text { et al }\end{array}$ & $\begin{array}{l}\text { Shi } \\
\text { et al }\end{array}$ & $\begin{array}{l}\text { Gao } \\
\text { et al }\end{array}$ & $\begin{array}{l}\text { Wang } \\
\text { et al }\end{array}$ & $\begin{array}{l}\text { Guo } \\
\text { et al }\end{array}$ & $\begin{array}{l}\text { Hou } \\
\text { et al }\end{array}$ & $\begin{array}{l}\text { Yang } \\
\text { et al }\end{array}$ & $\begin{array}{l}\text { Zhang } \\
\text { et al }\end{array}$ & $\begin{array}{l}\text { Cai } \\
\text { et al }\end{array}$ & $\begin{array}{l}\text { Qin } \\
\text { et al }\end{array}$ & $\begin{array}{l}\text { Xiao } \\
\text { et al }\end{array}$ & $\begin{array}{l}Y_{i} \\
\text { et }\end{array}$ \\
\hline $\begin{array}{l}\text { Clear description } \\
\text { of the } \\
\text { randomization? }\end{array}$ & $\mathrm{Y}$ & Y & $\mathrm{Y}$ & $Y$ & Y & Y & Y & $Y$ & $\mathrm{Y}$ & $\mathrm{Y}$ & Y & Y & Y & $\mathrm{Y}$ & $\mathrm{N}$ & Y & $Y$ \\
\hline $\begin{array}{l}\text { Clear description } \\
\text { of allocation or } \\
\text { concealment? }\end{array}$ & $Y$ & Y & $Y$ & Y & Y & Y & Y & $\mathrm{Y}$ & $\mathrm{Y}$ & $\mathrm{Y}$ & Y & Y & Y & $\mathrm{Y}$ & Y & Y & $Y$ \\
\hline $\begin{array}{l}\text { Complete } \\
\text { outcome data? }\end{array}$ & $Y$ & Y & Y & Y & Y & Y & Y & $\mathrm{N}$ & Y & $\mathrm{Y}$ & Y & Y & Y & $\mathrm{Y}$ & $\mathrm{N}$ & $\mathrm{Y}$ & $\mathrm{Y}$ \\
\hline $\begin{array}{l}\text { Low } \\
\text { withdrawal/drop- } \\
\text { out? }\end{array}$ & $\mathrm{Y}$ & Y & $\mathrm{Y}$ & $\mathrm{Y}$ & Y & Y & $\mathrm{Y}$ & $Y$ & $\mathrm{Y}$ & $\mathrm{Y}$ & $\mathrm{Y}$ & $\mathrm{Y}$ & Y & $\mathrm{Y}$ & $\mathrm{Y}$ & $\mathrm{Y}$ & $\mathrm{Y}$ \\
\hline $\begin{array}{l}\text { Reason for } \\
\text { studying specific } \\
\text { organisations }\end{array}$ & Y & $\mathrm{N}$ & Y & $\mathrm{N}$ & $\mathrm{N}$ & $\mathrm{N}$ & $\mathrm{N}$ & $\mathrm{N}$ & Y & $\mathrm{N}$ & $\mathrm{N}$ & Y & $\mathrm{N}$ & $\mathrm{Y}$ & $\mathrm{N}$ & Y & $\mathrm{N}$ \\
\hline $\begin{array}{l}\text { The influence of } \\
\text { the organisation } \\
\text { on the research }\end{array}$ & $\mathrm{N}$ & $\mathrm{N}$ & $\mathrm{N}$ & $\mathrm{N}$ & $\mathrm{N}$ & $\mathrm{N}$ & $\mathrm{N}$ & $\mathrm{N}$ & $\mathrm{N}$ & $\mathrm{N}$ & $\mathrm{N}$ & $\mathrm{N}$ & $\mathrm{N}$ & $\mathrm{N}$ & $\mathrm{N}$ & $\mathrm{N}$ & $\mathrm{N}$ \\
\hline $\begin{array}{l}\text { Researcher } \\
\text { influence in } \\
\text { qualitative and } \\
\text { mixed methods } \\
\text { studies }\end{array}$ & $\mathrm{N}$ & $\mathrm{N}$ & $\mathrm{N}$ & $\mathrm{N}$ & $\mathrm{N}$ & $\mathrm{N}$ & $\mathrm{N}$ & $\mathrm{N}$ & $\mathrm{N}$ & $\mathrm{N}$ & $\mathrm{N}$ & $\mathrm{N}$ & $\mathrm{N}$ & $\mathrm{N}$ & $\mathrm{N}$ & $\mathrm{N}$ & $\mathrm{N}$ \\
\hline $\begin{array}{l}\text { Support from } \\
\text { funding } \\
\text { agencies }\end{array}$ & $\mathrm{Y}$ & Y & $Y$ & $\mathrm{~N}$ & $\mathrm{Y}$ & $Y$ & $\mathrm{~N}$ & $\mathrm{Y}$ & $\mathrm{Y}$ & $\mathrm{N}$ & $\mathrm{Y}$ & $\mathrm{Y}$ & $\mathrm{N}$ & $Y$ & $\mathrm{~N}$ & $\mathrm{~N}$ & $\mathrm{Y}$ \\
\hline Total score (\%) & $75 \%$ & $63 \%$ & $75 \%$ & $75 \%$ & $75 \%$ & $75 \%$ & $75 \%$ & $50 \%$ & $75 \%$ & $75 \%$ & $75 \%$ & $75 \%$ & $50 \%$ & $75 \%$ & $25 \%$ & $75 \%$ & $7 !$ \\
\hline
\end{tabular}

\section{Figures}




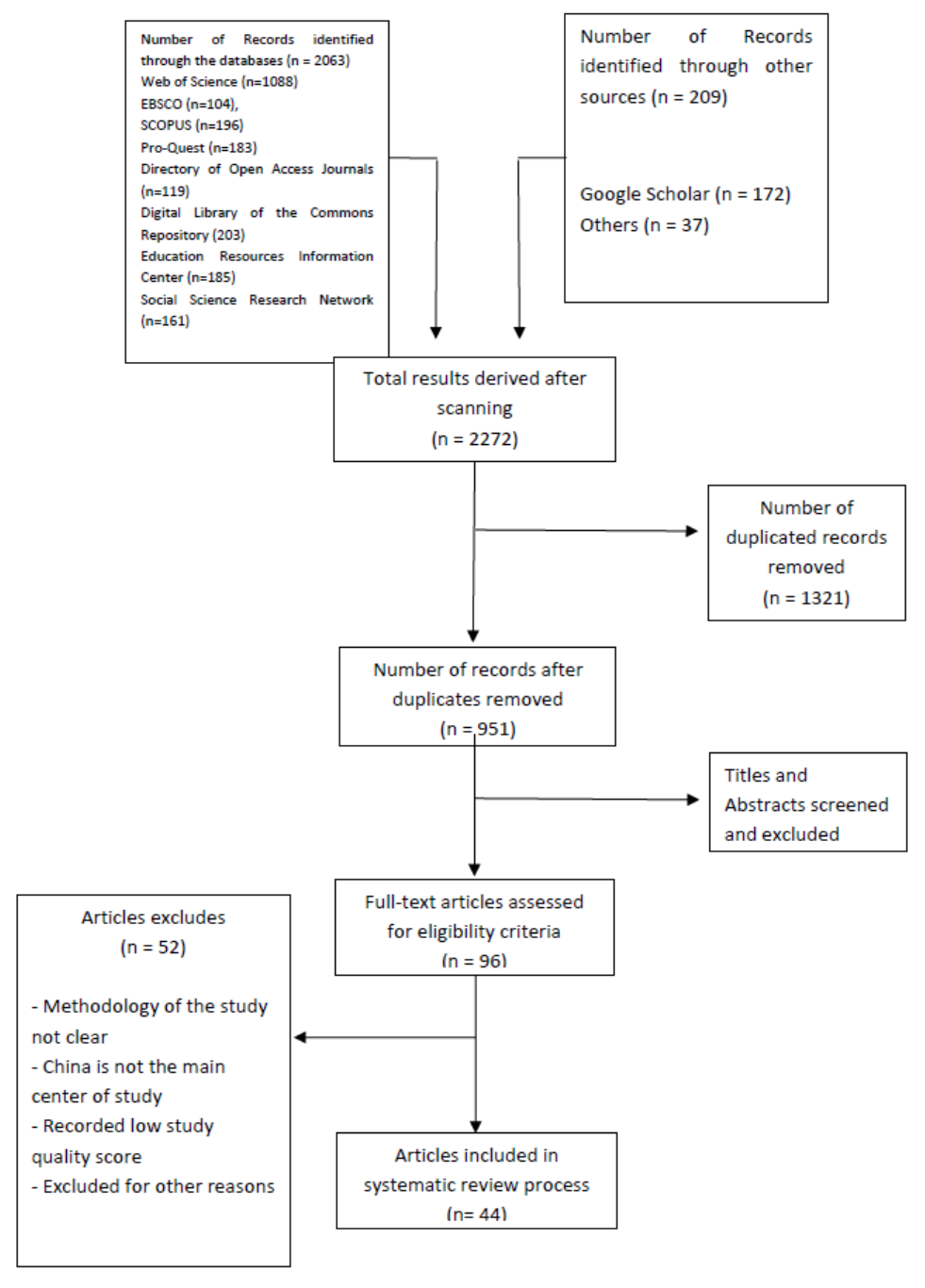

Figure 1

PRISMA Model 


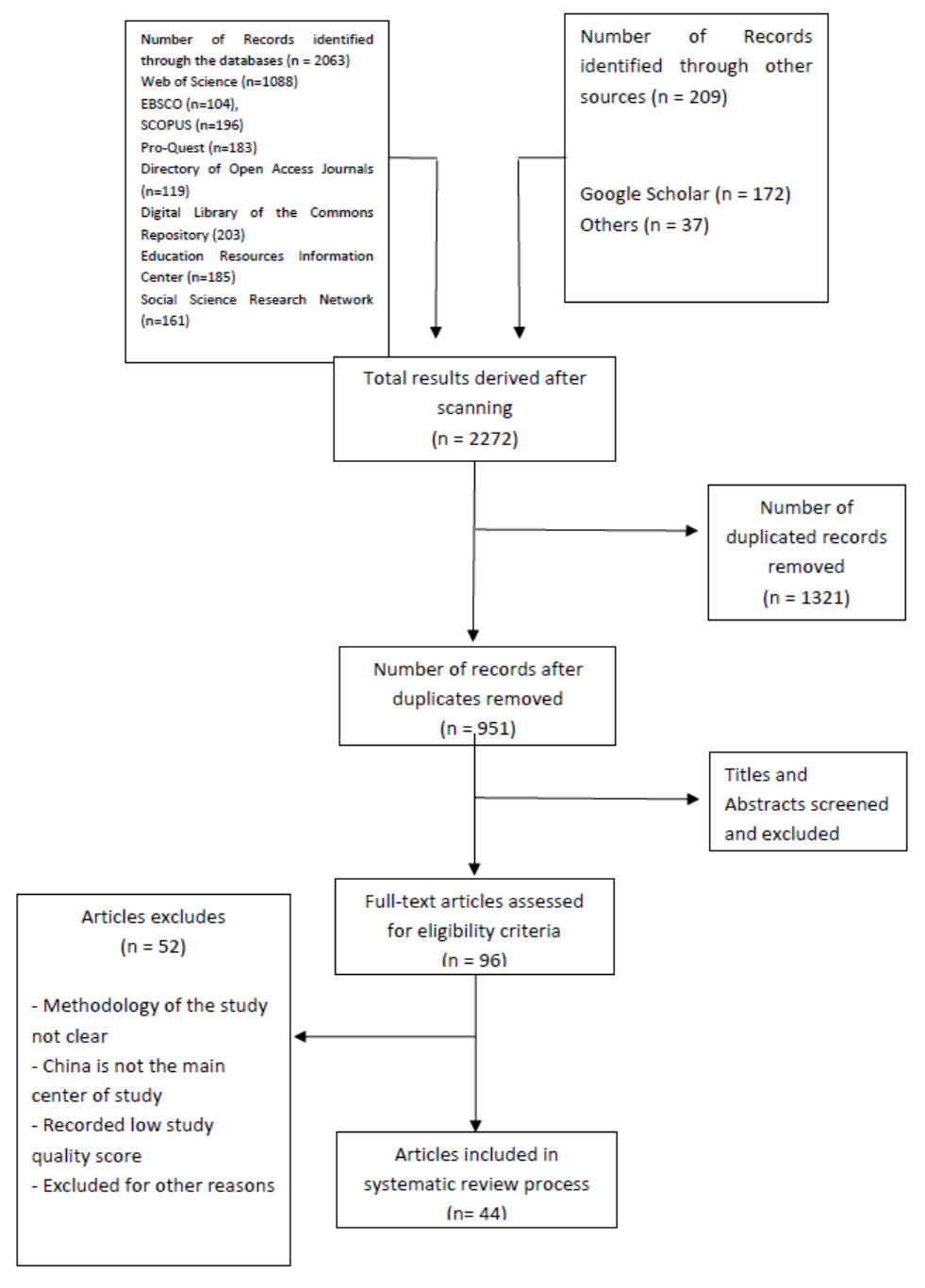

Figure 1

PRISMA Model 